\title{
A parameterization of size resolved below cloud scavenging of aerosols by rain
}

\author{
J. S. Henzing ${ }^{1}$, D. J. L. Olivié ${ }^{2}$, and P. F. J. van Velthoven ${ }^{1}$ \\ ${ }^{1}$ Royal Netherlands Meteorological Institute KNMI, De Bilt, The Netherlands \\ ${ }^{2}$ Meteo France, CNRM, Toulouse, France \\ Received: 28 October 2005 - Published in Atmos. Chem. Phys. Discuss.: 20 February 2006 \\ Revised: 19 June 2006 - Accepted: 29 June 2006 - Published: 14 August 2006
}

\begin{abstract}
A size dependent parameterization for the removal of aerosol particles by falling rain droplets is developed. Scavenging coefficients are calculated explicitly as a function of aerosol particle size and precipitation intensity including the full interaction of rain droplet size distribution and aerosol particles. The actual parameterization is a simple and accurate three-parameter fit through these precalculated scavenging coefficients. The parameterization is applied in the global chemistry transport model TM4 and the importance of below-cloud scavenging relative to other removal mechanisms is investigated for sea salt aerosol. For a full year run (year 2000), we find that below-cloud scavenging accounts for $12 \%$ of the total removal of super-micron aerosol. At mid-latitudes of both hemispheres the fractional contribution of below-cloud scavenging to the total removal of super-micron sea salt is about $30 \%$ with regional maxima exceeding 50\%. Below-cloud scavenging reduces the global average super-micron aerosol lifetime from 2.47 to 2.16 days in our simulations. Despite large uncertainties in precipitation, relative humidity, and water uptake by aerosol particles, we conclude that below cloud scavenging is likely an important sink for super-micron sized sea salt aerosol particles that needs to be included in size-resolved aerosol models.
\end{abstract}

\section{Introduction}

Aerosol removal processes remain an important source of uncertainty in global aerosol transport models (Rasch et al., 2000). Recent aerosol model intercomparisons such as AeroCom (AeroCom, 2005; Textor et al., 2006) show significant differences in modeled atmospheric aerosol concentrations that might be due to differences in the model representations of wet removal of aerosols. Aerosol particles are very effi-

Correspondence to: P. F. J. van Velthoven

(velthove@knmi.nl) ciently removed from the atmosphere by in-cloud and belowcloud scavenging processes. For accumulation mode aerosol the in-cloud removal, governed by aerosols serving as cloud condensation nuclei or ice nuclei and subsequent removal by precipitation, is by far the most efficient atmospheric sink. However, very small particles are more easily scavenged by rain droplets because they are rapidly transferred into falling droplets as their Brownian motion exceeds the rain droplet fall velocity. Coarse particles are also more easily scavenged than accumulation mode aerosols because of their size and inertness (Slinn, 1984; Pruppacher and Klett, 1997). Using explicit calculations of the efficiency of collision between size distributions of raindrops and aerosol particles, Andronache (2004) and Zhang et al. (2004) showed that even weak precipitation can remove $50-80 \%$ of the below-cloud aerosol in both number and mass.

On-line calculation of the full interaction between the size spectra of aerosol particles and precipitation, in order to obtain below-cloud scavenging parameters in large-scale aerosol models is (yet) unrealistic due to the large computational time involved. Therefore, studies often describe the size-resolved aerosol load as a diagnostic variable (Collins et al., 2001) or they confine themselves to precipitation free episodes so that wet removal can be neglected (Schulz et al., 1998; Vignati et al., 2001). Studies that do include size resolved below-cloud scavenging use constant scavenging parameters for aerosols that are confined to size-modes (Stier et al., 2005), use simple bulk parameterizations based on precipitation intensities (Balkanski, et al., 1993) or use approximate expressions for the scavenging rate based on e.g. mean rain droplet size (Gong et al., 2003a). Tost et al. (2006) actually calculate the size-dependent scavenging coefficients online, but they assume a monodisperse (rain) droplet spectrum. However, Andronache (2003) showed that the collision efficiency and thus the scavenging coefficients dependent strongly on the raindrop size.

Published by Copernicus GmbH on behalf of the European Geosciences Union. 
The purpose of this study is the development of a parameterization that provides the scavenging coefficient as a function of aerosol particle size and precipitation intensity. The parameterization consists of a simple fit through belowcloud scavenging coefficients calculated at high resolution. The calculations are based on the concept of efficiency of collision between polydisperse aerosol and raindrop distributions (Slinn, 1983; Pruppacher and Klett, 1997; Seinfeld and Pandis, 1998). This method is widely applied and has been evaluated (e.g. Mircea et al., 2000; Andronache, 2003, 2004; Zhang, 2004). The parameterization will be applied to size resolved sea salt aerosol in the global chemistry transport model TM4. The importance of below-cloud scavenging relative to other removal mechanisms will be discussed and the impact on the overall sea salt aerosol lifetime will be investigated.

\section{Below cloud scavenging coefficient}

\subsection{Explicit calculation}

A rain droplet with radius $R$, sweeps per unit of time approximately the volume of a cylinder equal to $\pi(R+r)^{2}\left(U_{t}-u_{t}\right)$, where $U_{t}$ is the droplet speed of fall, $u_{t}$ the aerosol particle speed of fall, and $r$ the aerosol particle radius. However, a falling droplet also perturbs the neighboring air and creates a flow-field around the droplet. Therefore, the actual volume swept by the falling droplet depends on the ability of the aerosol particle to adjust to the flow streamlines. The solution of this fluid mechanics problem is often expressed in terms of the collision efficiency $E(R, r)$, which is defined as the fraction of aerosol particles contained within the sweep-cylinder-volume that actually collides with the falling droplets. We can assume that the aerosol particle speed of fall is small compared to the rain droplet speed of fall and that the aerosol particle radius is small compared to the rain droplet radius. The differential scavenging coefficient $\beta$, which is the fractional amount (number, mass etc.) of aerosol removed by precipitation per unit time for a fixed aerosol particle radius, is then given by (Engelmann, 1968):

$\beta(r)=\int_{0}^{\infty} \pi R^{2} U_{t}(R) \varepsilon E(R, r) N(R) d R$,

where $N(R) d R$ is the number of rain droplets with radii between $R$ and $R+d R$ per unit volume and $\varepsilon$ is the retention efficiency that determines whether the collision between droplet and particle is effective. Below it is explained how the various terms that are necessary to perform the integration of Eq. (1) can be calculated.

\subsubsection{Rain droplet velocity}

In our calculations we will assume that rain droplets always fall at their terminal velocities. We base our rain droplet terminal velocity on an empirical representation given by Atlas et al. (1973) but for $R<0.3 \mathrm{~mm}$ we force the droplet velocity smoothly to zero using a linear fit to measurements of Gunn and Kinzer (1949) as proposed by Mätzler (2002). The pressure-independent droplet terminal velocity $\left[\mathrm{m} \mathrm{s}^{-1}\right]$ over the whole range is then given by:

$$
U_{t}(R)= \begin{cases}0 & ; R \leq 0.015 \mathrm{~mm} \\ 4.323(R-0.015) & ; 0.015 \leq R \leq 0.3 \mathrm{~mm} \\ 9.65-10.3 \exp (-0.3 R) & ; R>0.3 \mathrm{~mm}\end{cases}
$$

\subsubsection{Rain droplet size distribution}

We base our rain droplet size distribution on a gamma function fit of De Wolf (2001) to the pioneering size distribution measurements of Laws and Parsons (1943). We choose the gamma fit instead of the more traditional exponential function fit (Marshall and Palmer, 1948), because it represents the size distribution over the whole particle size spectrum whereas the exponential fits overestimate the number of droplets at the small end of the particle size spectrum. Making use of the droplet terminal velocity (Eq. 2), Mätzler (2002) properly normalized the De Wolf size distribution. Normalization assures that the precipitation intensity computed from the droplet size distribution (Eqs. 3a, b) and their accessory speed of fall (Eq. 2) is consistent with the rain rate input variable, $P$ (Eqs. 3a, b). The empirical expression for the number of drops with drop radii between $R$ and $R+\mathrm{d} R$, per unit volume of air, as a function of rain rate $P$ is given:

$$
\begin{aligned}
N(R, P)= & \operatorname{norm} \cdot 1.98 \cdot 10^{-5} P^{-0.384} R^{2.93} \\
& \exp \left[-\left(5.38 P^{-0.186} \cdot R\right)\right],
\end{aligned}
$$

where

norm $=1.047-0.0436 \cdot \ln P+0.00734 \cdot(\ln P)^{2}$.

The adopted rain droplet size distribution ("De Wolf") is shown in Fig. 1 for a precipitation intensity of $5 \mathrm{~mm} \mathrm{~h}^{-1}$.

\subsubsection{Raindrop-aerosol collection efficiency}

The collision efficiency, $E(R, r)$ expresses the probability that an aerosol particle that resides in the geometrical cylinder swept in a certain time interval by the cross-section of a falling rain droplet, actually collides with the droplet. We assume that every collision is efficient: the sticking efficiency or retention, $\varepsilon$, is unity (Pruppacher and Klett, 1997), in contrast to particle-particle collisions. The collection efficiency, $\varepsilon E$, is therefore equal to the collision efficiency. A value of $\varepsilon E=1$ implies that all particles in the geometric sweep-cylinder will be collected. In general $\varepsilon E \ll 1$, except for charged particles and very small Brownian particles (e.g. nanometer-sized particles formed by homogeneous nucleation) that are both not considered in our study. Theoretical solution of the Navier-Stokes equation for prediction of the collision efficiency for the general rain droplet-aerosol 


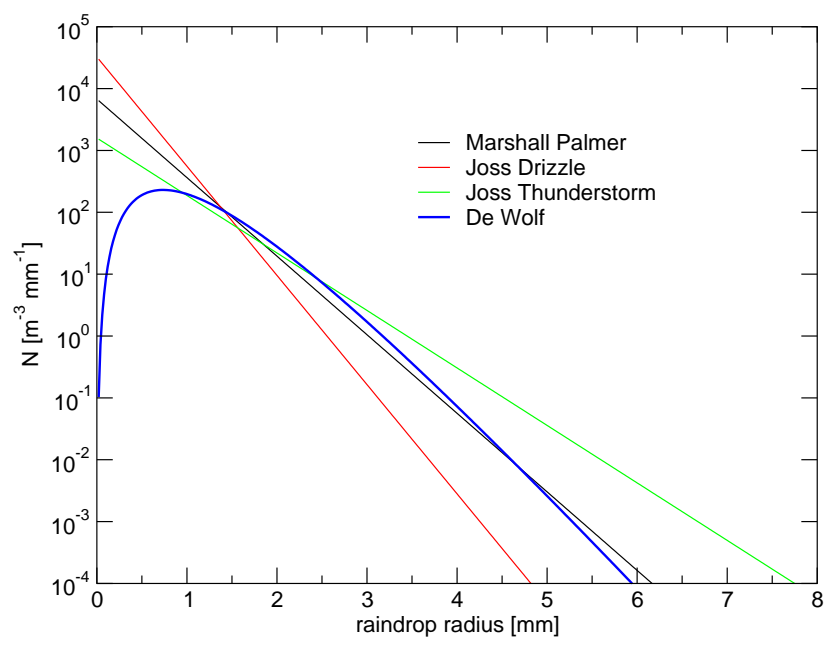

Fig. 1. The normalized rain droplet size distribution (precipitation intensity $5 \mathrm{~mm} \mathrm{~h}^{-1}$ ), as used in our study (De Wolf) together with three other widely used size distributions (for a discussion see Sect. 5).

interaction case is a difficult undertaking due to the complicated induced flow patterns around the falling drop. Instead of exactly solving the Navier-Stokes equations we use an alternative expression for $E$ that is based on dimensional analysis and experimental data (Slinn, 1984). The reader is referred to Seinfeld and Pandis (1998, their Sect. 20.3.1) for a full description of the applied $E$.

The scavenging coefficient $\beta$ as a function of aerosol particle radius and precipitation intensity is explicitly calculated using Eq. (1) and is shown in Fig. 2. The dark blue/black area in the figure clearly identifies the well-known Greenfield gap, where aerosols are not effectively removed by falling rain droplets. The strong increase in the scavenging coefficient at particle sizes of about $2 \mu \mathrm{m}$ marks the transition to the size region where inertial impaction becomes the dominant contributor to the collection efficiency.

\subsection{Parameterization}

To avoid the computationally expensive integration of Eq. (1) in our chemistry transport model, we fit an analytical function through the pre-calculated values of the scavenging coefficient for every aerosol particle radius (1000 log-equidistant increments per order of magnitude increase in particle radius) (Fig. 2). A function of the form

$\beta(P)=A_{0}\left(\mathrm{e}^{A_{1} P^{A_{2}}}-1\right)$,

fits the data quite well and yields a scavenging coefficient for every aerosol particle radius that is only a function of the precipitation intensity. Using the fit function instead of an explicit integration over the rain droplet spectrum introduces errors much smaller than $1 \%$ except in a very small size region around $1 \mu \mathrm{m}$ (Fig. 3).

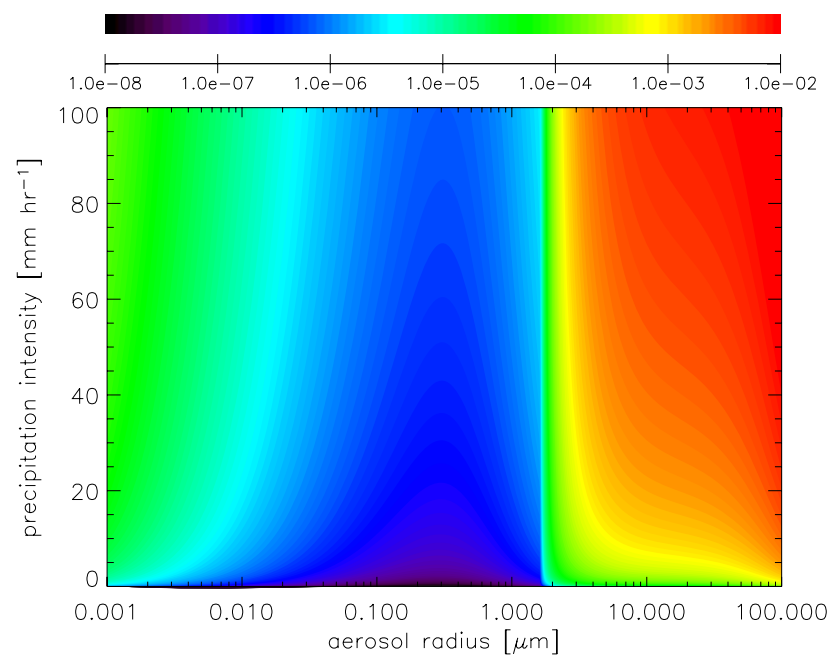

Fig. 2. Differential scavenging coefficient $\left[s^{-1}\right]$, scale is given in the color bar over the figure.

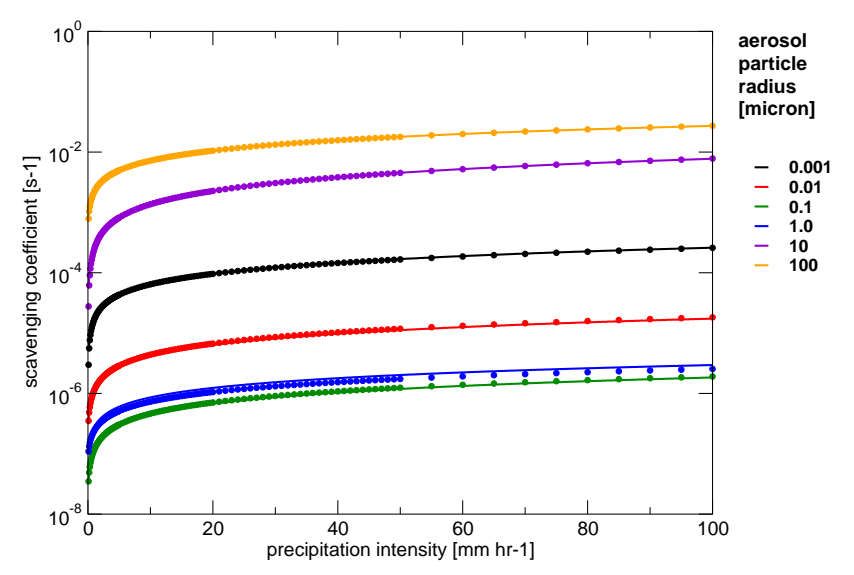

Fig. 3. Differential scavenging coefficients for a selection of aerosol radii (different colors). Full integrations of Eq. (1) are indicated by filled circles, results of the applied fit of Eq. (4) are indicated by full lines.

\section{Global chemistry transport model TM4}

The global chemistry transport model TM (Heimann, 1995; Dentener et al., 1999) contains an aerosol module (Jeuken, 2000; IPCC, 2001) that will be used to investigate the impact of the developed below cloud scavenging parameterization. $\mathrm{TM}$ is a three-dimensional transport model coupled off-line to ECMWF meteorological fields. Here, we use version 4 of TM that mainly differs from older versions by improved meteorological parameters. This version contains parameterizations of convective (Tiedtke, 1989) and turbulent tracer transport (Holtslag and Boville, 1993; Vogelezang and Holtslag, 1996; Beljaars and Viterbo, 1999). Large scale advection of aerosol tracers is performed using the slopes scheme of Russell and Lerner (1981). We use a horizontal resolu- 
tion of $6^{\circ}$ in longitude and $4^{\circ}$ in latitude. In the vertical the total number of hybrid $\sigma$-pressure levels (Simmons and Burridge, 1981) has been reduced from 60 (ECMWF) to 25 (TM4) by merging selected layers, mostly in the stratosphere. The scavenging parameterization will be evaluated for sea salt whose parameterization in the model was recently updated, as described below.

\subsection{Sea salt source function}

A source for sea salt aerosol particles (Gong, 2003b) that is based on the source function given by Monahan et al. (1986) has been included in the model. This source function, which is a function of the wind speed at $10-\mathrm{m}$ height $\left(U_{10}\right)$, provides the number of particles emitted in a certain size range per unit time and per unit sea surface:

$$
\frac{d F}{d r}=1.373 u_{10}^{3.41} r^{-A}\left(1+0.057 r^{3.45}\right) \cdot 10^{1.607 \mathrm{e}^{-B^{2}}}
$$

where $r$ is the particle radius at relative humidity $80 \%$, $A=4.7(1+\Theta r)^{-0.017 r^{-1.44}}, B=(0.433-\log r) / 0.433$, and $\Theta$ in $A$ is an adjustable parameter that controls the shape of the sub-micron size distribution. Here $\Theta=30$ as in Gong et al. (2003b). In our model the series of physical transport processes on sea salt aerosol are most conveniently formulated in terms of the dry part of the aerosol particles. Therefore, we have translated the source function, which is valid at $80 \%$ relative humidity (Monahan et al., 1983), in a dry particle source function using the size dependence of sea salt aerosol as a function of relative humidity given by Gerber (1985):

$r=\left[\frac{C_{1} r_{d}^{C_{2}}}{C_{3} r_{d}^{C_{4}}-\log R H}+r_{d}^{3}\right]^{1 / 3}$

where $r_{d}$ is the dry particle radius $[\mathrm{cm}], R H$ the relative humidity [\%], and $C_{1}(=0.7664)$, $C_{2}(=3.079), C_{3}\left(=2.5730 \cdot 10^{-11}\right), C_{4}(=-1.424)$ are parameters for different types of aerosol particles (values between brackets are valid for sea salt. To solve the size distribution both in number and mass it is sufficient to use 12 log-equidistant sectional bins (Gong et al., 2003a). Our 12 bins cover the dry radius spectrum from $0.03 \mu \mathrm{m}$ to $10.0 \mu \mathrm{m}$. Offline, we have calculated the mass emission $[\mathrm{kg}$ sea salt per second and per unit sea surface] in every bin of $1 \mathrm{~m} \mathrm{~s}^{-1}$ wind speed, from which the actual emission is obtained by multiplication with $U_{10}^{3.41}$ (Eq. 5). In the model, aerosol particles are assumed to be in a stable equilibrium size with respect to ambient relative humidity. The actual size of sea salt aerosol, which is used to calculate the below-cloud scavenging, is related to their dry size by the relationship of Gerber (1985).

\subsection{Aerosol sinks}

\subsubsection{Large scale cloud systems}

The change in aerosol mass mixing ratio $\mu$ due to the scavenging by precipitation can be obtained by applying an equivalent fractional loss term $f$ that accounts for the subgrid-scale patchiness of precipitation (Walton et al., 1988):

$\mu(t+\Delta t)=\mu(t) \cdot f \equiv \mu(t) \cdot\left(V_{1} f_{1}+V_{2} f_{2}+V_{3}\right)$,

where indices $i=1-3$ represent respectively the region inside precipitating clouds, the region below precipitating clouds, and cloud free regions, $V_{i}$ is the fraction of the grid cell occupied by region of type $i$, and $f_{i}=\exp \left[-\beta_{i} \Delta t\right]$ where $\beta_{i}$ is the scavenging coefficient for region of type $i$ and $\Delta t$ is the time between two calls of the removal scheme. Volume $V_{1}$ is simply the cloud fraction. Volume $V_{2}$ (below precipitating cloud) is the fraction of the cell that is cloud free but overcast (using the maximum overlap assumption). Volume $V_{3}$ is cloud free and there are no clouds in overlying layers. The assumption of an equivalent fractional loss term implicitly assumes that aerosols are uniformly distributed within each grid cell. We observed that when this scheme is applied at high temporal resolution, aerosol is removed too efficiently. The explanation is that it is implicitly assumed that aerosol is mixed from aerosol rich (cloud free) regions into aerosol poor (precipitating) regions after every removal step whereas in reality the precipitating systems still affect, for a large part, the same aerosol containing air mass. To overcome this problem, we effectively postpone the mixing. To do so we defined a no-mixing-timescale, $\Delta t_{\text {no-mix }}=N \cdot \Delta t$, where $N$ is an adjustable parameter, and we reformulated the equivalent fractional loss term that then becomes a function of the number of calls, $n$, of the removal scheme since the last mixing instant:

$f^{*}(n)=\frac{V_{1} f_{1}^{n}+V_{2} f_{2}^{n}+V_{3}}{V_{1} f_{1}^{n-1}+V_{2} f_{2}^{n-1}+V_{3}}$.

If we neglect all other processes but the removal scheme we find for $n=N$ :

$$
\begin{aligned}
& \mu(t+N \Delta t)=f^{*}(N) \cdot \mu(t+(N-1) \Delta t), \\
& \mu(t+N \Delta t)=f^{*}(N) \cdot f^{*}(N-1) \cdot \ldots . . \cdot f^{*}(1) \cdot \mu(t), \\
& \mu(t+N \Delta t)=\left(V_{1} f_{1}^{N}+V_{2} f_{2}^{N}+V_{3}\right) \cdot \mu(t),
\end{aligned}
$$

which equals the mixing ratio that would be obtained if air masses and precipitating clouds would be kept fixed at their relative positions for a time period $\Delta t_{\text {no-mix }}$. A convenient assumption for the no-mixing-timescale is the time between successive updates of the meteorological input, which is six hours in our model. 


\section{Below cloud scavenging}

The differential scavenging coefficient, $\beta(r)$, obtained up to now, corresponds to a given, fixed aerosol particle radius. To derive an integral scavenging coefficient that is valid for the total aerosol mass contained within a certain size bin, Eq. (1) has to be integrated over the aerosol particle mass distribution (Dana and Hales, 1976):

$\beta\left(r_{s}\right)=\int_{r_{l}}^{r_{r}} \beta(r) f_{\text {mass }}(r) d r$

where $r_{l}$ and $r_{r}$ are the left and right borders of the size bin, $f_{\text {mass }}(r) \mathrm{d} r$ is the mass probability distribution function (pdf), and subscript "s" indicates that the scavenging coefficient is obtained by integration over the aerosol mass spectrum that is contained in the size bin. Within a size bin the mass-pdf is unknown. As a first approximation we simply assume that the mass is equally distributed within a bin. The resolution with respect to aerosol radius of the parameterized differential scavenging coefficients is chosen such that the scavenging coefficient at the exact radius of the (wet) size bin borders can be obtained by linear interpolation of adjacent scavenging coefficients without introducing additional errors $(\ll 1 \%)$. A table with the selected coefficients $A_{0}-A_{2}$ that are used to calculate the differential scavenging coefficients with Eq. (4) are available at http://www.knmi.nl $/ \sim$ velthove/wet_deposition.

\section{In-cloud scavenging}

The in-cloud scavenging coefficient is determined by two sequential steps: In the first step cloudwater is formed from water vapor. Here, we neglect the existence of interstitial aerosol and thus assume that all aerosol particles act as condensation nuclei. All aerosol is therefore included in the cloudwater that is formed. In the second step precipitation is formed from the aerosol-containing cloudwater. The precipitation formation rate thus fully determines the removal process (Roelofs and Lelieveld, 1995). The actual scavenging coefficient is the fraction of cloud water that is converted into rain water per unit of time.

\subsubsection{Dry deposition}

Dry deposition, the amount of material deposited to a unit surface area per unit time, $F$, is calculated as:

$F=-v_{d} C$,

where the constant of proportionality, $v_{d}$, with units of length per unit time is the deposition velocity. The dry deposition velocity of aerosol particles is a function of turbulent state of the atmosphere and of particle aerodynamic size. Based on theoretical considerations Slinn and Slinn (1980) derived an expression for the deposition velocity,

$v_{d}=\frac{\left(v_{a}+v_{g}\right)\left(v_{b}+v_{g}\right)}{\left(v_{a}+v_{b}+v_{g}\right)}$,

where $v_{a}, v_{b}$, and $v_{g}$ are velocities. Velocity $v_{a}$, represents the rate of material transport by turbulence from a reference height in the free troposphere to a layer of stagnant air just above and adjacent to the surface (quasi-laminar sublayer). In our model $v_{a}=1 / r_{a}$, where $r_{a}$ is the aerodynamic resistance that is calculated and stored at ECMWF. Analogously, the transfer velocity in the quasi-laminar sublayer is written $v_{b}=1 / r_{b}$, where $r_{b}$ is the resistance to transfer which depends upon Brownian diffusion accounted for by the Schmidt number $(S c)$, and upon inertial impaction, accounted for by the Stokes number (St) (Slinn, 1982):

$r_{b}=\frac{1}{u_{*}\left(s c^{-2 / 3}+10^{-3 / S t}\right)}$,

where $u_{*}$ is the friction velocity, $S c=v / D$, where $v$ is the kinematic viscosity and $D$ the Brownian diffusion and $S t=v_{g} u_{*}^{2} / g v$, where $g$ is the gravitational acceleration. The gravitational settling velocity is given by Stokes Law,

$v_{g}=\frac{4 \rho_{p} r_{p}^{2} g}{18 \mu}$,

where $\rho_{p}$ is the density of the particle, $r_{p}$ is the particle radius, $\mu$ is the viscosity of air.

\subsubsection{Convective cloud systems}

The scavenging by convective precipitation is proportional to the mass flux entrained in convective clouds, as in Balkanski et al. (1993) and Guelle et al. (1998). We apply rather arbitrary scavenging efficiencies of 50\% for shallow convection up to $700 \mathrm{hPa}$ and of $80 \%$ for deep convection. Furthermore, we include an exponential scaling factor to avoid removal in the case of relatively dry updrafts. In the absence of precipitation there is no removal, for a precipitation intensity of $1 \mathrm{~mm} / \mathrm{h}$ the scaling is 0.85 , and for higher intensities the scaling rapidly goes to 1 (no scaling).

\section{Results}

\subsection{Emission, load, and lifetime}

Applying our model with the newly implemented sea salt source function (Gong, 2003b), we find for the year 2000 a total sea salt mass emission of $2440 \mathrm{Tg}$ for particles with dry radii between 0.03 and $10 \mu \mathrm{m}$. This value falls well within the range of estimates reported in the literature (1000 to $3000 \mathrm{Tg} / \mathrm{yr}$, Erickson and Duce, $1988 ; 5900 \mathrm{Tg} / \mathrm{yr}$, Tegen et al., 1997) and can be compared to the current best estimate 


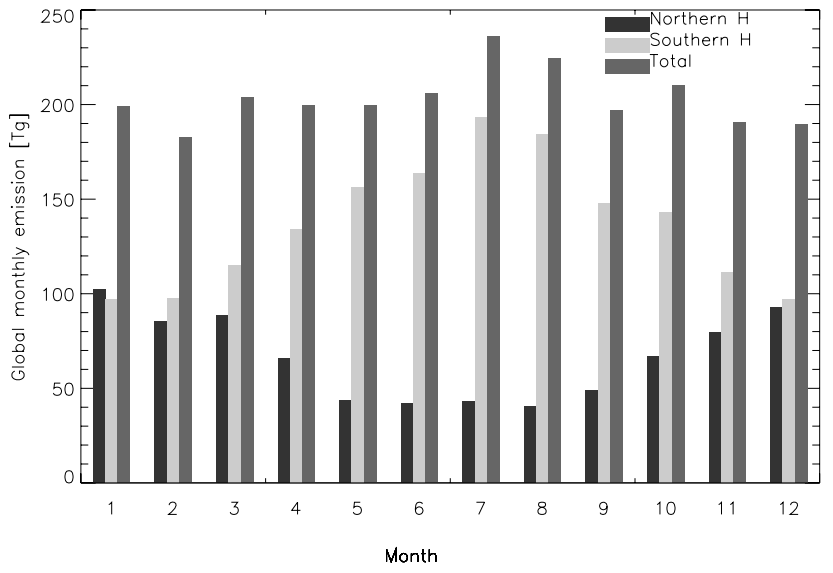

Fig. 4. Simulated monthly variations of global and hemispheric sea salt emissions for the year 2000.

of $3300 \mathrm{Tg} / \mathrm{yr}$ for sea salt particles with dry radii between 0.03 and $8 \mu \mathrm{m}$ that is given in IPCC (2001). Super-micron (sub-micron) aerosol particles by definition have diameters larger (smaller) than $1 \mu \mathrm{m}$. Super-micron (sub-micron) mass emissions add to 2.390 (48) $\mathrm{Tg} / \mathrm{yr}$, which agrees with the ranges of 1000 to 6000 (18 to 100$) \mathrm{Tg} / \mathrm{yr}$ provided by IPCC (2001). In Fig. 4 we show the seasonal variations of global and hemispheric monthly emissions in our model. The strong seasonal variations in both the northern and southern hemisphere agree with the findings of Gong et al. (2002).

Guelle et al. (2001) used the Monahan (1986) source function for sea salt to estimate a mean annual global mass-load of 0.5 and $10.6 \mathrm{Tg}$ for submicron and supermicron (cut off at $4 \mu \mathrm{m}$ radius). Using the Gong-Monahan source, that mainly differs from the original Monahan source function at small particle sizes, which make up only a small fraction of the total mass, we find for size ranges corresponding to Guelle et al. global mean loads of 0.5 and $6.1 \mathrm{Tg}$ for submicron and supermicron aerosol, respectively. For the whole size range we find $9.8 \mathrm{Tg}$ which can be compared to Guelle et al. (2001) who have $12.7 \mathrm{Tg}$.

For IPCC (2001) six models with prescribed sea salt sources were run to estimate global burdens. Using these estimates the average sea salt lifetime (average of all models) for the whole size range is 2.1 days (different model results vary between 0.8 and 4.55 days). Our estimate of 2.16 days is in close agreement with these values.

We compared simulated (year 2000) sea salt mixing ratios in the surface layer with long term measurements of sea salt aerosols on a global scale (Gong et al., 2002). Generally, seasonally averaged model results agreed with observations within a factor of two (not shown). Comparisons for a number of locations (Table 1) are shown in Fig. 5. For northern Atlantic locations (Mace Head and Heimaey), the model predictions agree well with observations in terms of both concentration and seasonal variation, despite the fact
Table 1. The sea salt measurement stations for intercomparisons.

\begin{tabular}{llcc}
\hline Station Name & Location & Latitude & Longitude \\
\hline Mace Head & Ireland & 53.33 & -9.90 \\
Heimay & Iceland & 63.25 & -20.15 \\
Oahu & Hawaii (USA) & 21.33 & -157.70 \\
Cape Grim & Australia & -40.68 & 144.68 \\
George von Neumayer & Antarctica & -70.65 & -8.25 \\
Alert & Canada & 82.47 & -62.50 \\
Bermuda & UK & 32.32 & -65.27 \\
Palmer Station & Antarctica & -64.92 & -64.05 \\
\hline
\end{tabular}

that concentrations in a single year vary more from month to month than long term averaged concentrations. For Oahu, a systematic under-estimate of sea salt aerosol concentration is simulated, which resembles the under-estimate found by Gong et al. (2002). Gong et al. (2002) suggest that incorrectly predicted mean wind speeds in their model cannot explain the under-estimate. Since wind observations are assimilated in the ECMWF model, which provides our model with meteorological fields, we believe that the discrepancy cannot be explained by erroneous winds (Caires and Sterl, 2003). Although there are many factors controlling the sea salt concentration in a certain location, we believe that too effective removal by convective precipitating systems is responsible for the systematic under-estimate. For Antarctic locations (George von Neumayer and Palmer Station) the model overestimates the sea salt aerosol concentration in the austral winter, whereas model predictions and observations are in closer agreement the rest of the year. High predicted concentrations at Palmer Station in July may be explained by extraordinary synoptic activity at the end of the month. However, June and May did not show extreme winds compared to other years. The differences can neither be explained by the coarse model horizontal resolution and the fact that the Antarctic stations are near the coast. Even model grid cells that lie more inland show predicted sea salt concentrations that are too high in the austral winter. Moreover, when moving inland the prediction for the other months becomes significantly lower than the (coastal) observations. We do not have an explanation for the discrepancy, which deserves more attention in the future. For Cape Grim, Alert, and Bermuda the predicted sea salt concentrations seems reasonable and year to year meteorological differences may explain the highly variable behavior of the predicted concentrations.

\subsection{Partitioning between below-cloud scavenging and other sinks}

For the 12 dry sea salt tracers global-average fractional contributions of dry deposition (dry), removal in convective cloud systems (convective), removal by large-scale clouds (in-cloud), and below-cloud scavenging by falling raindrops 

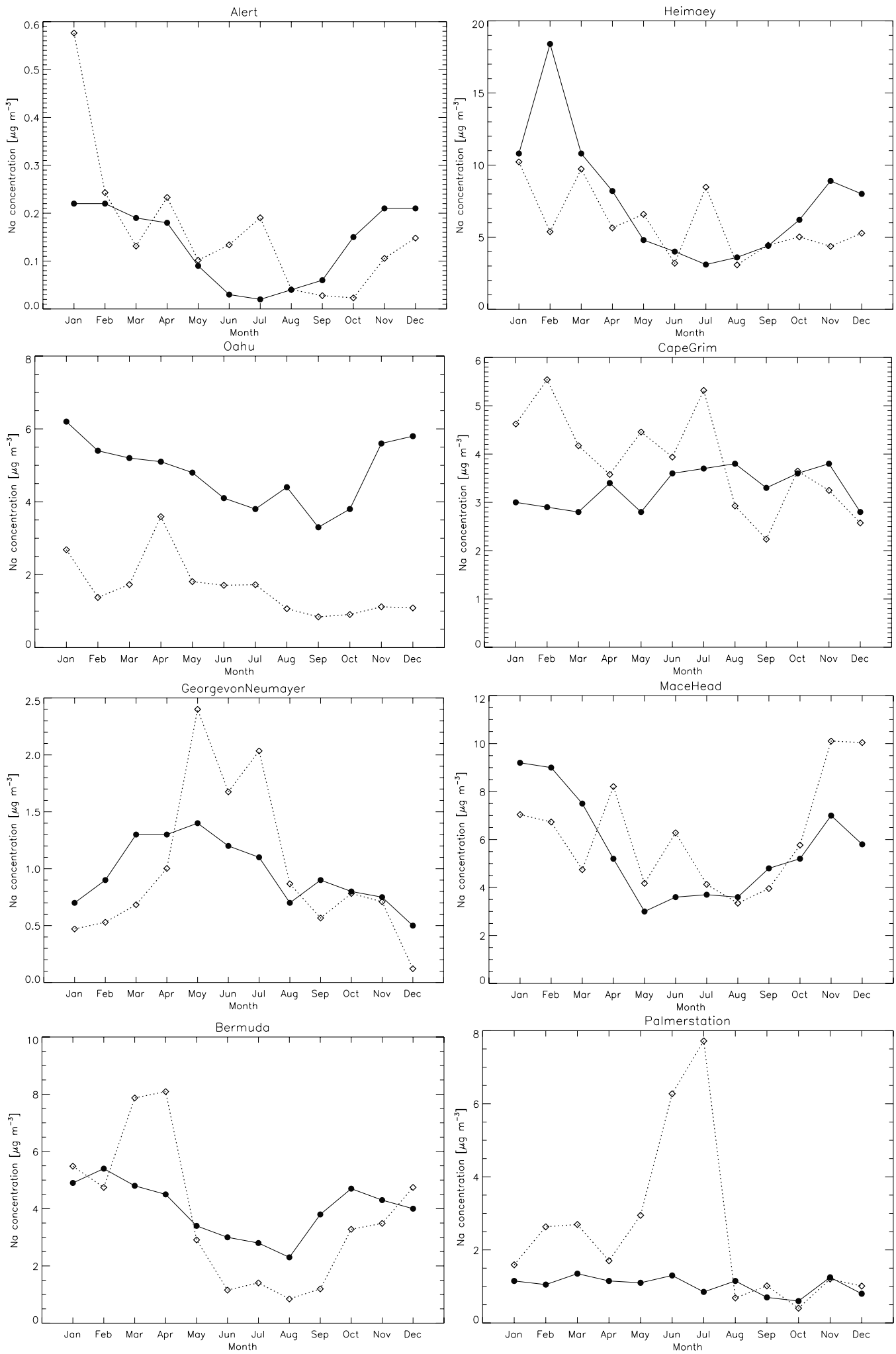

Fig. 5. Intercomparison of predicted (year 2000) and observed (long term measurements) monthly mean sea salt concentrations at selected stations. Measurement locations are listed in Table 1. Measurements indicated by filled circles are connected by solid lines. Model simulations are indicated by open diamonds. 


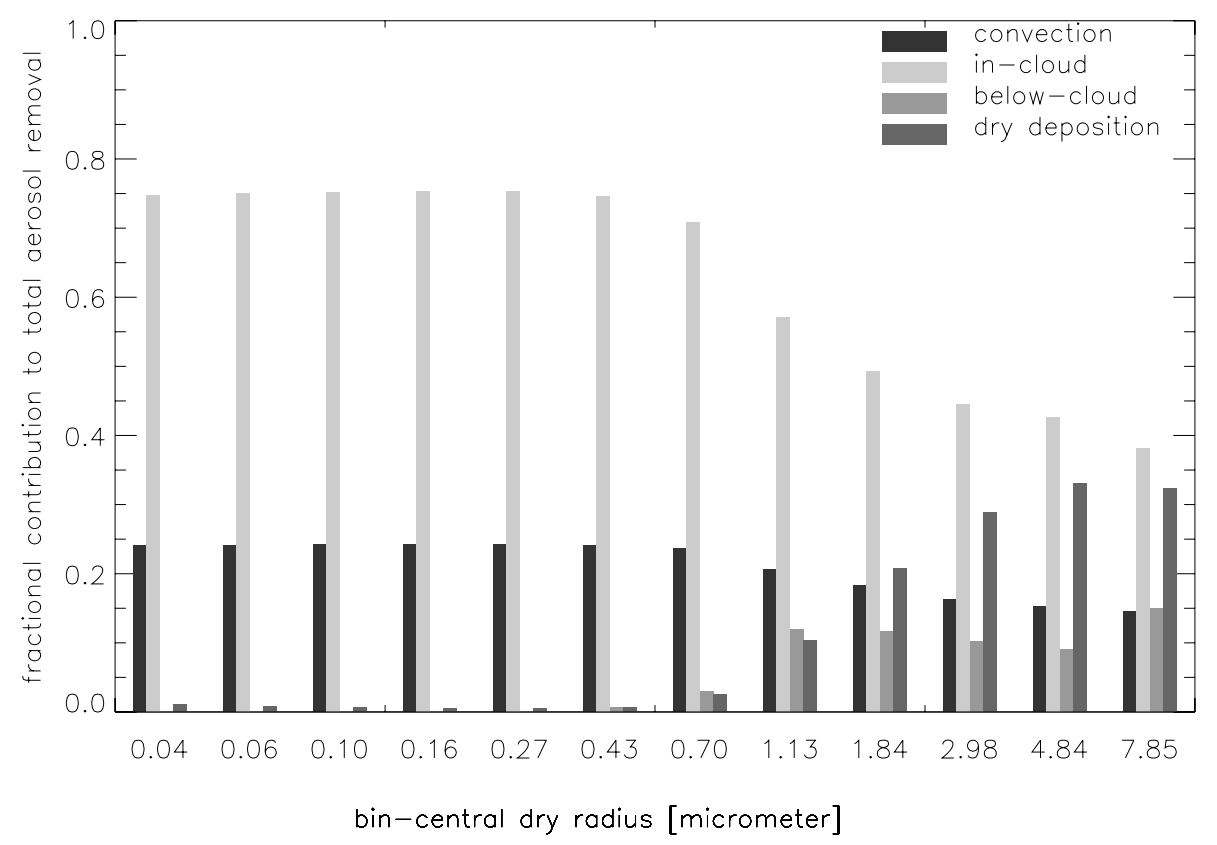

Fig. 6. Globally-averaged relative importance of different removal mechanisms for sea salt aerosols for the year 2000. The log-central radii of the 12 (dry) sea salt bins are given in micrometer. "in-cloud" here refers to large scale systems without convection.

(below-cloud) to the total aerosol removal are shown in Fig. 6. For sub-micron particles removal is governed by cloud processes with in-cloud dominating over convective; below-cloud scavenging thus being unimportant. For supermicron sea salt the individual fractional contributions to the total removal are $0.29,0.16,0.43$, and 0.12 for dry, convective, in-cloud, and below-cloud removal, respectively. All considered removal processes thus contribute significantly to the total removal of super-micron aerosol.

In Fig. 7 the global distribution of the relative contribution of below-cloud scavenging to the total sea salt removal is shown. At mid-latitudes in both hemispheres below-cloud scavenging is regionally the dominant sink for super-micron sea salt. The maximum below-cloud scavenging contributions coincide with yearly averaged maxima in sea salt emissions. Very similar patterns are also found for dry deposition (not shown). Removal processes that act so efficiently in the vicinity of source regions may very efficiently prevent the tracer from being transported to other regions. It is therefore tempting to hypothesize that ignoring e.g. the below-cloud scavenging process would have an even stronger effect on the global average aerosol lifetime than can be expected from the global fractional contribution of the below-cloud scavenging to the total removal. However, below we will show that this is not the case. Aerosol lifetime $\tau$, can be defined as the ratio of the atmospheric burden of aerosol to its emission. For sufficiently long run time periods emission is balanced by removal. Total removal is the sum of all individual removal processes so that the inverse of the overall lifetime can be written as the sum of the inverse lifetimes of each of the in- dividual removal processes:

$$
\frac{1}{\tau_{\text {tot }}}=\frac{1}{\tau_{\text {dry }}}+\frac{1}{\tau_{\text {convective }}}+\frac{1}{\tau_{\text {in-cloud }}}+\frac{1}{\tau_{\text {below-cloud }}},
$$

where individual lifetimes are defined as the ratio of the atmospheric burden to the removal caused by the individual process. The total lifetime and the contributions to it by the individual processes are shown in Table 2. When all processes are considered, the total atmospheric lifetime is 2.16 days. If one of the processes would not occur the total atmospheric lifetime would increase. The increase in total atmospheric lifetime can thus also be inferred from model simulations with individual removal processes switched off. Running TM4 without below-cloud scavenging, we find $\tau_{\text {tot }}=2$.47. If we use Eq. (15) to predict the total atmospheric lifetime in the absence of below-cloud scavenging from the model simulation that includes all removal processes and the simulations with the individual other removal processes switched off, we also find $\tau_{\text {tot }}=2.47$ days. This confirms the validity of Eq. (15) and implies that the individual lifetimes or individual fractional contributions to total removal can directly be compared to assess their relative importance.

\section{Remaining uncertainties}

We have parameterized the scavenging of aerosol particles by falling rain droplets and have shown that for particles with diameters larger than one micrometer below cloud scavenging is an important process to be included in models, especially when the modeling objective is to simulate aerosol 
Table 2. Aerosol lifetimes, $\tau$, for super-micron sea salt particles for a model simulation with and a simulation without the below-cloud scavenging parameterization. Subscripts "dry", "below-cloud", "in-cloud”, and "convective" refer to dry deposition, below cloud scavenging, scavenging in large scale clouds, and scavenging by convective clouds, respectively.

\begin{tabular}{lcccc}
\hline Process & \multicolumn{2}{c}{ All Removal processes } & \multicolumn{2}{c}{ No below-cloud scavenging } \\
Lifetime & $\begin{array}{c}\text { Fractional contribution } \\
\text { total removal }\end{array}$ & Lifetime & $\begin{array}{c}\text { Fractional contribution } \\
\text { total removal }\end{array}$ \\
\hline Dry & 7.43 & 0.29 & 7.77 & 0.32 \\
Below-cloud & 17.43 & 0.12 & - & - \\
In-cloud & 5.07 & 0.43 & 4.85 & 0.51 \\
Convective & 13.64 & 0.16 & 14.38 & 0.17 \\
Total & 2.16 & 1.00 & 2.47 & 1.00 \\
\hline
\end{tabular}

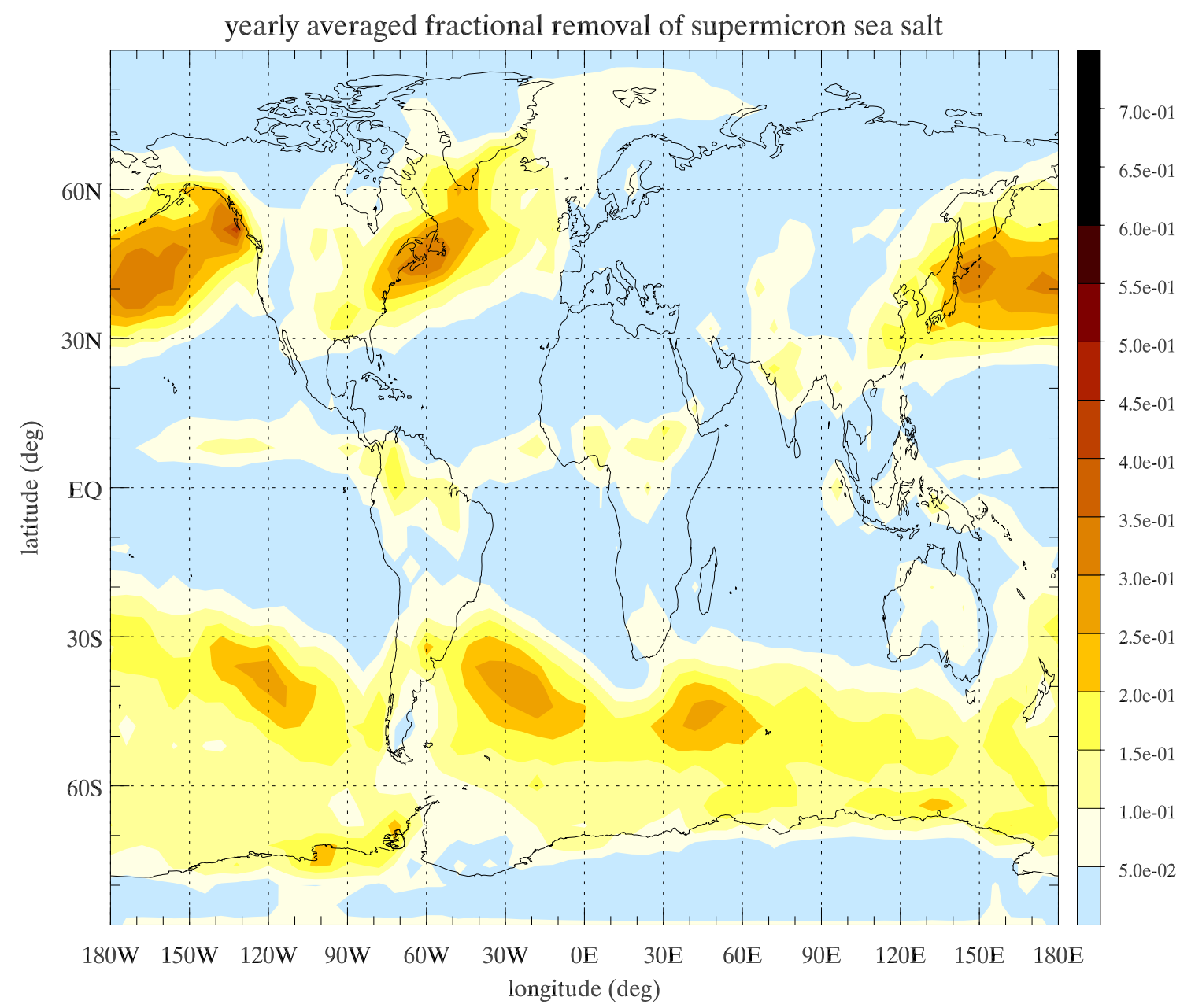

Fig. 7. Average fractional contribution of below-cloud scavenging to the total removal of super-micron sea salt aerosol for the year 2000 .

mass (rather than number). We also made it plausible that the new parameterization itself (i.e. the fit through precalculated scavenging coefficients and conversion from differential scavenging coefficients to integral scavenging coefficients that are valid for an aerosol size bin) is quite accu- rate numerically. So far, however, we have not yet discussed physical uncertainties e.g. related to the choice of the rain droplet spectrum or particle humidity growth. Below we give an overview of the most relevant issues. 


\subsection{Rain droplet spectrum}

Differential scavenging coefficients depend strongly on the choice of the rain droplet size distribution. The gamma distribution we have chosen (fit parameters specified by Eqs. 3a, b) represents global average continues rainfall. It is unlikely that the rain droplet distributions of individual precipitating systems are properly described with this specific distribution. Therefore, we also determined the differential scavenging coefficients using Eq. (1) with the three other rain droplet size distributions that are shown in Fig. 1. The "Marshall Palmer" distribution is the widely used exponential fit of Marshall and Palmer (1948) to the Laws and Parsons (1943) data that is also used by De Wolf (2001). Droplet distributions associated with drizzle and precipitation from thunderstorms are dominated by small and large droplets, respectively. The Joss (Joss et al., 1968) "drizzle" and "thunderstorm" exponential distributions (Fig. 1) can be expected to indicate extremes in this case. However, De Wolf (2001) found that a gamma function fit to the data (Laws and Parsons, 1943) represents the measurements at the small end of the droplet range $(R<0.5-1 \mathrm{~mm})$ better than exponential functions that predict maximum droplet number concentration for droplets with sizes approaching zero diameter. Therefore, the distribution used in this study has fewer small rain droplets, which are very effective aerosol collectors, than the other distributions show in Fig. 1. Results from the "Thunderstorm" distribution pretty much resembled our results, but the "Marshall Palmer" and "Drizzle" distributions yielded scavenging coefficients that were a factor of 3 and 5, respectively, higher over the whole range of precipitation intensities and for all aerosol particles sizes. The "De Wolf" distribution plus the additionally investigated rain droplet distributions do not encompass the whole range of possible rain droplet size distributions (for an overview see Pruppacher and Klett, 1997) so that deviations could potentially be even larger. Moreover, the distributions are the same everywhere below precipitating clouds, whereas it is known that large differences in rain droplet spectra may occur between cloud base and surface due to e.g. breakup and evaporation of large droplets and coagulation of droplets. It is not possible to produce reliable rain droplet size distributions with our model, nor can we integrate the aerosol and rain droplet size distributions to obtain the scavenging coefficients online. As yet it is thus not possible to get around the droplet size distribution problem. This would require an explicit microphysical package to be included which for the moment is numerically too expensive for our model.

\subsection{Particle humidity growth}

Another possible source of uncertainty is the growth of particles with increasing humidity. For the water uptake of sea salt particles we applied a relation provided by Gerber (1985). In our model sea salt is externally mixed with other aerosol particles. Applying the Gerber relation implicitly assumes that the composition of our sea salt resembles that of the Navy Aerosol Model (NAM). In reality, sea salt particles may act as a substrate for heterogeneous chemistry and will therefore be internally mixed to some extent (Dentener and Crutzen, 1993). Internal mixing of sea salt particles with continental pollution and organic compounds reduces their hygroscopic growth rate (Swietlicki, 2000; Randles et al., 2004). For below-cloud scavenging this may become important for aerosol particles with radii around 1 or $2 \mu \mathrm{m}$ where the differential scavenging coefficient grows very rapidly with increasing aerosol particle size. Keeping track of internal mixtures combined with online particle humidity growth calculations is not foreseen in our model in the near future, but it is in principle possible. A related issue is the accuracy of the relative humidity itself, especially at high relative humidity. At the coarse resolution used here $\left(6^{\circ} \times 4^{\circ}\right)$ a single, using only an average, value of the relative humidity in each cell is a poor representation of the spatial variability of relative humidity. The large changes in relative humidity fields that are experienced between successive meteo updates, especially in situations with precipitation, indicates that the model neither represents temporal variability well. Moreover relative humidity may not be accurately predicted below precipitating clouds. The importance of uncertainties related to relative humidity may be best demonstrated with an example: The aerosol mass (including associated water) of a sea salt particle with dry radius $1 \mu \mathrm{m}$ will be underestimated by a factor 2 if the ambient relative humidity of $90 \%$ is underestimated at $80 \%$, the corresponding underestimate in the differential scavenging coefficient is more than a factor of 20 .

\subsection{Precipitation and evaporation}

Below-cloud scavenging is directly proportional to the precipitation intensity. Uncertainties in precipitation intensity stem from uncertainties in the distribution of precipitation in time and space and in the calculated precipitation formation rates. Determination of the raining fraction of a model grid cell is difficult. Wilcox and Ramanathan (2004) show that it is likely that most models underestimate the raining fraction. In our model, precipitation is assumed to be distributed uniformly over the cloud covered fraction within the grid cell so that it is more likely that we overestimate the raining fraction. Furthermore, precipitation is assumed to be distributed over the period between two meteo updates. In reality it may not rain continuously; some of the clouds in the domain may not precipitate at all and thus leave the aerosol unaffected. Our precipitation intensities will thus likely be biased towards lower values. For lower intensities, the rain drop size distribution will consist of more and smaller-sized droplets that scavenge aerosols more easily. Together this will overestimate removal of aerosol particles by below-cloud scavenging. Secondly, the precipitation formed in a grid cell is 
(almost) always larger than the precipitation intensities at the surface given by the ECMWF data. Part of this difference may be explained by evaporation. Therefore, we scale our precipitation formation rates with ECMWF surface precipitation implicitly handling the evaporation of rain droplets. Uncertainties in ECMWF precipitation will thus directly translate to uncertainties in below-cloud scavenging. Moreover, when falling rain droplets evaporate the aerosol particles that resided in the droplet are released. In our approach the aerosol is released within the cloud and aerosols remain prone to in-cloud scavenging. However, in reality most of the evaporation will take place below cloud base and aerosols are only scavenged by falling rain droplets. Evaporation of falling rain droplets may be an effective downward transport mechanism for aerosol and once properly accounted for may increase the relative contribution of below-cloud scavenging compared to that of in-cloud scavenging. In a (near) future version of the model evaporation fields stored experimentally by ECMWF will be used to investigate this issue further.

The parameterization for below-cloud aerosol scavenging presented in this paper is valid for liquid precipitation. However, part of the yearly precipitation is solid, especially at higher latitudes and altitudes and this has influenced the estimates of the fractional contribution of below-cloud scavenging to the total scavenging in regions or seasons with wintry conditions. When studying cold seasons or regions in more detail, a parameterization for below-cloud aerosol scavenging by solid precipitation would be needed. Development of such a parameterization is beyond the scope of this paper. Moreover, such a development is hindered by the poor understanding of the processes involved in snowfall scavenging despite ongoing experimental and theoretical efforts (Pruppacher and Klett, Ch. 17; Puxbaum and Wagenbach, 1998)

\section{Conclusions}

A size dependent parameterization for the removal of aerosol particles by falling rain droplets has been developed. The parameterization has been applied in the global chemistry transport model TM4 and the relative importance of below-cloud scavenging relative to other removal mechanisms has been investigated. To investigate the impact of below-cloud scavenging we have adopted a source for sea salt aerosol (Gong, 2003b). A scheme with 12 log-equidistant bins covering the dry aerosol spectrum from 0.03 to $10.0 \mu \mathrm{m}$ keeps track of the aerosol size distribution. We have shown that our modeled results fall well within the range of current models. We have also shown that in general and on a global scale simulated sea salt concentrations agree well with long term observations in terms of both concentration and seasonal variation. However, at some locations (e.g. Antarctica and Oahu) we found differences that we could not readily explain.

For a full year run (year 2000), we find that for particles with diameter larger than $1 \mu \mathrm{m}$, below-cloud scavenging is as important as the removal in convective updrafts and that below-cloud scavenging accounts for $12 \%$ of the total yearly average removal. At mid-latitudes of both hemispheres the fractional contribution of below-cloud scavenging to the total removal is about $30 \%$ with regional maxima exceeding $50 \%$. The maxima in relative importance of below-cloud scavenging coincide with maxima in emissions. Excluding the below-cloud scavenging process would result in an increase of global average aerosol lifetime from 2.16 days to 2.47 days.

Despite uncertainties in the obtained deposition by belowcloud scavenging by uncertainties in precipitation, relative humidity, and particle humidity growth, we conclude that below cloud scavenging is likely an important sink for supermicron sized sea salt aerosol particles. The same conclusion would not necessarily hold for other super-micron sized particles such as e.g. desert dust. Desert dust is produced in arid areas under dry conditions. Therefore, dust is lifted and transported from its source regions and resides generally in the lower free troposphere, whereas coarse mode sea salt remains in the boundary layer.

Edited by: A. Laaksonen

\section{References}

AeroCom: http://nansen.ipsl.jussieu.fr/AEROCOM/, global aerosol model Intercomparison, 2005.

Andronache, C.: Estimated variability of below-cloud aerosol removal by rainfall for observed aerosol size distributions, Atmos. Chem. Phys., 3, 131-143, 2003, http://www.atmos-chem-phys.net/3/131/2003/.

Andronache, C.: Estimates of sulfate aerosol wet scavenging coefficient for locations in the Eastern United States, Atmos. Environ., 38, 795-804, 2004.

Atlas, D., Srivastava, R. C., and Sekhon, R. S.: Doppler radar characteristics of precipitation at vertical incidence, Rev. Geophys., 11, 1-35, 1973.

Balkanski, Y. J., Jacob, D. J., Gardner, G. M., Graustein, W. C., and Turekian, K. K.: Transport and residence times of tropospheric aerosols inferred from a global three-dimensional simulation of 210Pb, J. Geophys. Res., 98(D11), 20 573-20 586, 1993.

Beljaars, A. C. M. and Viterbo, P.: Role of the boundary layer in a numerical weather prediction model, in: Clear and cloudy boundary layers, edited by: Holtslag, A. A. M. and Duynkerke, P. G., NH-publishers, 287-304, 1999.

Caires, S. and Sterl, A.: Validation of ocean wind and wave data using triple collocation, J. Geophys. Res., 108(C3), 3098, doi:10.1029/2002JC001491, 2003.

Collins, W. D., Rasch, P. J., Eaton, B. E., Khattatov, B. V., Lamarque, J.-F., and Zender, C. S.: Simulating aerosols using a chemical transport model with assimilation of satellite aerosol retrievals: Methodology for INDOEX, J. Geophys, Res., 106(D7), 7313-7336, 2001.

Dana, M. T. and Hales, J. M.: Statistical aspects of the washout of polydisperse aerosols, Atmos. Environ., 10, 45-50, 1976. 
Dentener, F. and Crutzen, P. J.: Reaction of $\mathrm{N}_{2} \mathrm{O}_{5}$ on tropospheric aerosols: Impact on the global distribution of $\mathrm{NO}_{\mathrm{x}}, \mathrm{O}_{3}$, and $\mathrm{OH}$, J. Geophys. Res., 98, 7149-7163, 1993.

Dentener, F., Feichter, J., and Jeuken, A.: Simulation of the transport of Rn222 using on-line and off-line global models at different horizontal resolutions: a detailed comparison with measurements, Tellus, 51B, 573-602, 1999.

de Wolf, D. A.: On the Laws-Parsons distribution of raindrop sizes, Radio Sci., 36, 639-642, 2001.

Engelmann, R. J.: The calculation of precipitation scavenging, in: Meteorology and Atomic Energy, edited by: Slade, D. H., USAEC 68-60097, 1968.

Erickson III, D. J. and Duce, R. A.: On the global flux of atmospheric sea salt, J. Geophys. Res., 93, 14 079-14 088, 1988.

Fitzgerald, J. W., Marti, J. J., Hoppel, W. A., Frick, G. M., and Gelbard, F.: A one-dimensional sectional model to simulate multicomponent aerosol dynamics in the marine boundary layer 2 . Model application, J. Geophys. Res., 103(D13), 16 103-16117, 1998.

Gerber, H. E.: Relative-humidity parameterization of the Navy Aerosol Model (NAM), NRL Report 8956, Naval Research Laboratory, Washington, D.C., 1985.

Gong S. L., Barrie, L. A., and Lazare, M.: Canadian aerosol module (CAM): A size-segregated simulation of atmospheric aerosol processes for climate and air quality models 2 . Global seasalt aerosol and its budgets, J. Geophys. Res., 107(D24), 4779, doi:10.1029/2001JD002004, 2002.

Gong, S. L., Barrie, L. A., Blanchet, J.-P., v. Salzen, K., Lohmann, U., Lesins, G., Spacek, L., Zhang, L. M., Girard, E., Lin, H., Leaitch, R., Leighton, H., Chylek, P., and Huang, P.: Canadian Aerosol Module: A size-segregated simulation of atmospheric aerosol processes for climate and air quality models, 1, Module development, J. Geophys. Res., 108(D1), 4007, doi:10.1029/2001JD002002, 2003a.

Gong, S. L.: A parameterization of sea-salt aerosol source function for sub and super-micron particles, Global Biogeochem. Cycles, 17(4), 1097, doi:10.1029/2003GB002079, 2003b.

Guelle, W., Balkanski, Y. J., Schulz, M., Dulac, F., and Monfray, P.: Wet deposition in a global size-dependent aerosol transport model 1. Comparison of a 1 year ${ }^{210} \mathrm{~Pb}$ simulation with ground measurements, J. Geophys. Res., 103(D10), 11429 $11445,1998$.

Guelle, W., Schulz, M., and Balkanski, Y.: Influence of the source formulation on modeling the atmospheric global distribution of sea salt aerosol, J. Geophys. Res., 106(D21), 27 509-27 524, 2001.

Gunn, R. and Kinzer, G. D.: The terminal velocity of fall for water droplets in stagnant air, J. Meteorol., 6, 243-248, 1949.

Heimann, M.: The global atmospheric tracer model TM2, Tech. Rep. 10, Deutsches Klimarechenzentrum, Hamburg, Germany, 1995.

Holtslag, A. A. M. and Boville, B. A.: Local versus nonlocal boundary-layer diffusion in a global climate model, J. Climate, 6, 1825-1842, 1993.

IPCC, Climate Change 2001: The scientific basis, Contribution of Working Group I to the Third Assessment Report of the Intergovernmental Panel on Climate Change, Cambridge University Press, 881 p., 2001.

Jeuken, A. B. M.: Evaluation of chemistry and climate models us- ing measurements and data assimilation, Ph.D. Thesis, Technical University of Eindhoven, 2000.

Joss, J., Thams, J. C., and Waldvogel, A.: The variation of raindrop size distributions at Locarno, in: Proc. Internat. Conf. on cloud physics, 369-373, 1968.

Laws, J. O. and Parsons, D. A.: The relationship of raindrop size to intensity, Trans. AGU, 24, 452-460, 1943.

Mätzler, C.: Drop-size distributions and Mie computations for rain, IAP research report, 2002-16, 2002.

Marshall, J. S. and Palmer, W. M.: The distribution of raindrop with size, J. Meteorol. Soc., 5, 165-166, 1948.

Mircea, M., Stefan, S., and Fuzzi, S.: Precipitation scavenging coefficient: influence of measured aerosol and raindrop size distributions, Atmos. Environ., 34, 5169-5174, 2000.

Monahan, E. C., Spiel, D. E., and Davidson, K. L.: Model of marine aerosol generation via whitecaps and wave disruption, Preprint Volume, 9th conference on aerospace and aeronautical meteorology, American Meteorological Society, Boston, 147-152, 1983.

Monahan, E. C., Spiel, D. E., and Davidson, K. L.: A model of marine aerosol generation via whitecaps and wave disruption, in: Oceanic Whitecaps, edited by: Monahan, E. C. and Mac Niocaill, G., 167-174, D. Reidel, Norwell, Mass., 1986.

Pruppacher, H. R. and Klett, J. D.: Micronphysics of clouds and precipitation, 2nd ed., 954 p., Kluwer Academic Publishers, 1997.

Puxbaum, H. and Wagenbach, D.: guest editors, special issue Atmos. Environ., 32, ALPTRAC: High alpine aerosol and snowchemistry, 3923-4085, 1998.

Randles, C. A., Russell, L. M., and Ramaswamy, V.: Hygroscopic and optical properties of organic sea salt aerosol and consequences for climate forcing, Geophys. Res. Lett., 31, L16108, doi:10.1029/2004GL020628, 2004.

Rasch, P. J., Feichter, J., Law, K., et al.: A comparison of scavenging and deposition processes in global models: Results from the WCRP Cambridge workshop of 1995, Tellus, 52, 1025-1056, 2000.

Roelofs, G.-J. and Lelieveld, J.: Distribution and budget of $\mathrm{O} 3$ in the troposphere calculated with a chemistry general circulation model, J. Geophys. Res., 100(D10), 20 983-20 998, 1995.

Russell, G. L. and Lerner, J. A.: A new finite-differencing scheme for the tracer transport equation, J. Appl. Meteorol., 20, 14831498, 1981.

Schulz, M., Balkanski, Y. J., Guelle, W., and Dulac, F.: Role of aerosol size distribution and source location in a threedimensional simulation of a Saharan dust episode tested against satellite-derived optical thickness, J. Geophys. Res., 103(D9), 10 579-10 592, 1998.

Seinfeld, J. H. and Pandis, S. N.: Atmospheric Chemistry and Physics, Wiley, New York, pp. 1326, 1998.

Simmons, A. J. and Burridge, D. M.: An energy and angularmomentum conserving vertical finite-difference scheme and hybrid vertical coordinates, Mon. Wea. Rev., 109, 758-766, 1981.

Slinn, S. A. and Slinn, W. G. N.: Prediction for particle deposition on natural waters, Atmos. Environ., 14, 1013-1016, 1980.

Slinn, W. G. N.: Prediction for particle deposition to vegetative canopies, Atmos. Environ., 16, 1785-1794, 1982.

Slinn, W. G. N.: Precipitation scavenging, in: Atmospheric Science and Power Production, edited by: Randerson, D., Doc. DOE/TIC-27601, Tech. Inf. Cent., Off. Of Sci. and Tech. Inf., 
U.S. Dep. Of Energy, Washington, D.C., 466-532, 1984.

Stier, P., Feichter, J., Kinne, S., Kloster, S., Vignati, E., Wilson, J., Ganzeveld, L., Tegen, I., Werner, M., Balkanski, Y., Schulz, M., Boucher, O., Minikin, A., and Petzhold, A.: The aerosolclimate model ECHAM5-HAM, Atmos. Chem. Phys., 5, 11251156, 2005,

http://www.atmos-chem-phys.net/5/1125/2005/.

Swietlicki, E., Zhou, J., Covert, D. S., Hameri, K., Busch, B., Vakeva, M., Dusek, U., Berg, O. H., Wiedensohler, A., Aalto, P., Mäkelä, J., Martinsson, B. G., Papaspiropoulos, G., Mentes, B. Frank, G., and Stratmann, F.: Hygroscopic properties of aerosol particles in the north-eastern Atlantic during ACE-2, Tellus, 52B, 201-227, 2000.

Tegen, I., Hollrig, P., Chin, M., Fung, I., Jacob, D., and Penner, J. E.: Contribution of different aerosol species to the global aerosol extinction optical thickness: Estimates from model results, J. Geophys. Res., 102, 23 895-23 915, 1997.

Textor, C., Schulz, M., Guibert, S., Kinne, S., Balkanski, Y., Bauer, S., Berntsen, T., Berglen, T., Boucher, O., Chin, M., Dentener, F., Diehl, T., Easter, R., Feichter, H., Fillmore, D., Ghan, S., Ginoux, P., Gong, S., Grini, A., Hendricks, J., Horowitz, L., Huang, P., Isaksen, I., Iversen, T., Kloster, S., Koch, D., Kirkevåg, A., Kristjansson, J. E., Krol, M., Lauer, A., Lamarque, J. F., Liu, X., Montanaro, V., Myhre, G., Penner, J., Pitari, G., Reddy, S., Seland, Ø., Stier, P., Takemura, T., and Tie, X.: Analysis and quantification of the diversities of aerosol life cycles within AeroCom, Atmos. Chem. Phys., 6, 1777-1813, 2006, http://www.atmos-chem-phys.net/6/1777/2006/.
Tiedtke, M.: A comprehensive mass flux scheme for cumulus parameterization in large-scale models, Mon. Wea. Rev., 117, 1779-1800, 1989.

Tost, H., Jöckel, P., Kerkweg, A., Sander, R., and Lelieveld, J.: Technical note: A new comprehensive SCAVenging submodel for global atmospheric chemistry modelling, Atmos. Chem. Phys., 6, 565-574, 2006, http://www.atmos-chem-phys.net/6/565/2006/.

Vignati, E., de Leeuw, G., and Berkowicz, R.: Modeling coastal aerosol transport and effects of surf-produced aerosols on processes in the marine atmospheric boundary layer, J. Geophys. Res., 106(D17), 20 225-20 238, 2001.

Vogelezang, D. H. P. and Holtslag, A. A. M.: Evaluation and model impacts of alternative boundary-layer height formulations, Bound.-Layer Meteorol., 81, 245-269, 1996.

Walton, J. T., MacCracken, M. C., and Ghan, S. J.: A global-scale lagrangian trace species model of transport, transformation, and removal processes, J. Geophys. Res., 93(D7), 8339-8354, 1988.

Wilcox, E. M. and Ramanathan, V.: The impact of observed precipitation upon the transport of aerosols from South Asia, Tellus, 56B, 435-450, 2004.

Zhang, L., Michelangeli, D. V., and Taylor, P. A.: Numerical studies of aerosol scavenging by low-level, warm stratiform clouds and precipitation, Atmos. Environ., 38, 4653-4665, 2004. 